\title{
Metaphors in A World Without Thieves (2004): An Epitome of Social Class in Contemporary China
}

\author{
YAN Yan \\ University of Connecticut, Storrs, USA
}

\begin{abstract}
In the current social milieu, audiences are familiar with the entertaining effects of commercial films. However, I argue that by incorporating metaphors, the commercial films can fulfill a pedagogical function and embed ideological correctness in its texts. Such function departs its original role and goes beyond entertaining effects. As films can mirror social realities, in some particular situations, it can serve as a moral guard by conveying pedagogical meanings and terrifying effects. It regulates and warns the mass to obey the social rules in a subtle way. This essay is in an attempt to tackle how the commercial film generates didactical effects, and how metaphors facilitate to fulfill such goal. I take A World Without Thieves as a case study to illustrate how the commercial film fulfills its pedagogical function through textual analysis. In my personal opinion, what makes this film stand up and worthy of scholarly discussion, is that the metaphors not only mirror the class stratification in contemporary Chinese society, but also turn an entertaining film into a pedagogical one. The metaphors also highlight an imbalanced landscape between social power and individual experience in contemporary China, which is usually invisible in current milieu. In brief, the metaphors in film serve as cultural interventions that illustrate the dialectics and invisible landscape of today’s China.
\end{abstract}

Keywords: commercial film, metaphor, pedagogical function

In a temple of Tibet, a woman worships the Buddha statues faithfully. In a reverse shot, a young peasant worker is varnishing a Buddha statue. This is the debut of the protagonists: Li Wang (Rene Liu), who is a senior thief and the young worker Shagen (Baoqiang Wang). The camera adopts a parallel montage to display their first encounter. In the meanwhile, a man with cynical smiles (Andy Lau) is wandering through the crowd who are worshipping the Buddha statues; he takes the chance to steal purses and cell phones from the crowd. Then, there is a close-up shot on a drop of falling varnish while Shagen is painting the Buddha's statue; then the camera adopts a 180-degree reverse shot of $\mathrm{Li}$, which indicates her transformation from a thief to a renewed person with good virtues. In contrast, the man's cynicism is outlined in a reversal angle shot; his sunglasses mirror an up-side-down candy box. The three sets of paralleled hemisected frames are collaged in one frame, accompanying with heavy metal sound track; such setting conveys a rich hue of metaphor.

The above-mentioned scene is from A World Without Thieves (2004), directed by Feng Xiaogang, a well-known Chinese filmmaker of commercial film. In current social milieu, people are familiar with the entertaining effects of commercial films. However, I argue that by incorporating metaphors, the commercial films can fulfill a pedagogical function and embed ideological connotations in its texts. Such function departs

YAN Yan, Ph.D. candidate, Instructor, Program of Comparative Literacy and Cultural Studies, Department of Literatures, Cultures and Languages, University of Connecticut, Storrs, USA. 
its original role and goes beyond entertaining effects. The director accentuates a terrifying effect on moral decay through depicting the fate of a thief couple. Film can mirror social realities; in particular situations, it serves as a moral guard by conveying pedagogical meanings and terrifying effects. It regulates and warns the mass to obey the social rules in a subtle way. In this essay, in an attempt to tackle how the commercial film generates didactical effects, and how metaphors facilitate to fulfill such goal, I take $A$ World Without Thieves as a case study to illustrate how the commercial film fulfills its pedagogical function through textual analysis. In my personal opinion, what makes this film pop up and worthy of scholarly discussion, is that the metaphors not only mirror the class stratification in contemporary Chinese society, but also tint an entertaining film with pedagogical tones. The metaphors also highlight an imbalanced landscape between social power and individual pursuit in contemporary China, which is usually invisible in current milieu. In brief, the metaphors in film serve as cultural interventions that map out the dialectics and invisible landscape of today’s China.

\section{Theoretical Framework}

Metaphor widely exists; it structures the most essential foundation of language and cognition. It is more than a decorative mechanism, but a central process in language and cognition. According to Lakoff (1980), metaphors construct our conceptual system and our understanding of the world. Metaphors link two conceptual domains, the "source" domain and the "target" domain. The source domain entails literal entities, features, discourses, and relationships, which are located in the mind. These entities are expressed in language through interrelated words and expressions. The target domain is relatively abstract compared to the source domain. It takes the configuration from the source domain, through the metaphorical connection. Target domains are considered to be relevant to entities, discourses, and relationships, which could be located in the source domain.

In this essay, cognitive metaphor theory constructs the theoretical framework. The works of Lakoff and Johnson (1980a; 1980b; 1999), Lakoff and Turner (1989), and Lakoff (1987; 2001a; 2001b), offer an introduction to the cognitive theory of metaphor, as well as unveiling cultural, artistic, and ideological implications of the metaphor. Cognitive metaphor theory considers metaphor as an omnipresent and fundamental existence in the realm of language and cognitions. It claims that "our ordinary conceptual system is fundamentally metaphorical in nature” (Lakoff \& Johnson, 1980a, p. 3), which indicates that most of our concepts and discourses are structured and understood in terms of conceptualizations.

Metaphor exists in film as a means of expression; it shapes our experiences and constructs our representations, as well as offering construction of the characters and understanding. Through the metaphorical expressions, we can perceive discourses, plots, and features of the characters in the film. In brief, metaphor is crucial in interpreting texts (Semino, 2008); it negotiates the interactions between two domains. Metaphor can also serve as an organizing principle to organize the narrative and convey meanings in the texts through the interaction of cognitive structures (Goatly, 2007, pp. 21-22).

\section{The Terrifying Force of Commercial Film}

Retrospection on the history of Chinese national film reveals a tradition that film harbors a function of legend-making and legitimizing. In China, since its inception, films have shouldered the responsibilities of constructing positive images of political, ideological, and cultural significance in society. However, the emergence of commercial film broke this stiff situation. Besides entertaining the audience, commercial films also have another function which is usually ignored by the audience and film critics, such as serving as an 
admonishing force to the audience. The logic of commercial films represents ideologies and core values of the mainstream society. The logic embedded in commercial films also demonstrates entrenched values upheld by mainstream society, such as very limited tolerance to misbehaves—adultery and unloyalty.

So far, little attention has been given to the pedagogical significance that commercial film harbors and how the commercial film employs metaphors to fulfill such goal. To be more specific, in this commercial film, a romanticized tragedy is displayed through fetishizing religious mysticism; a sacredness of maternity and intensified stupid innocence are delineated as well. The metaphors in this film help to construct a binary-polar duality, literally, the good and the evil, which can be categorized into two types: figured metaphor, such as the police officers serve as the sign of authority; and the animated metaphor: wolves and sheep refer to good and evil people.

The space and cities are also constructed in a metaphorical way. The plot is set on a train from Tibet to Beijing. Therefore, this film displays a symbolic journey: the starting point, Tibet serves as a symbol of pureness and innocence in human nature and utopian; the destination, Beijing, links to chaotic metropolitan cities. People originally from Tibet are constructed to have good virtues, while people from Beijing, such as Bo, $\mathrm{Li}$, and Uncle $\mathrm{Li}$, are morally corruptive. The director constructs a utopian world with nostalgia and allegorical textures that aim at highlighting the erosion of humanity in modern society. The opening space is set in a Tibetan plateau, which serves as a symbol of spiritual purity. In brief, the setting of space creates a comparable binary between Tibet and Beijing in a metaphorical tone, thus subtly conveys the theme of the film: the good and the evil.

In the opening sequence, Li Wang is tutoring a wealthy man English in a luxury villa. While this rich man attempts to conduct sexual assault to $\mathrm{Li}$, Bo hides in the bathroom and records the whole process with a hand-held digital camera. Subsequently, they corporate to conspiracy and blackmail a BMW car from the wealthy man. In this film, the rich man represents a degraded class who shows the greedy side of human nature. This plot also reveals a prevailing social phenomenon of injustice and dramatically growing income inequality. The plot also maps out a cultural space: The emotional anxieties are caused by social unevenness. This strategy links to the social condition in China.

The protagonist's name, Shagen, literally means "silly root”. In a metaphorical sense, he is portrayed as the innocent "sheep". Shagen is an orphan; he grows up in an innocent environment of the countryside, where people had never stolen anything. He believes that no one would hurt him since a flock of wolves did not. Such cognition ignores the fact that the existence of evil is the world. Shagen earns money by building Buddhist temples in Tibet. After five years’ hard work, he has a saving of $¥ 60,000$ (\$9,000 USD). He plans to go back to his hometown and get married with all his savings. So, he brings all his money while taking the train, where various people display their distinctive goals and personalities. With an outspoken personality, he immediately becomes the target of a gang of thieves led by Uncle Li and the thief expert Bo Wang. Shagen demonstrates the ideal aspects of human nature: benevolence, innocence, and unstained naivete. He harbors a faithful belief in humanity. However, as naively holding an illusion that this is a world without thieves, this figure also carries a sentimental aura.

In particular, at the first acquaintance, when $\mathrm{Li}$ and Shagen first met in the desert (after Li broke up with Bo and was left alone), Shagen gives Li a lucky pendant. He believes that the lucky pendant will bless Li and bring her good luck. It also serves as a symbol of redemption and rescue, and represents the power of virtue and 
the enlightenment of love. Later, touched by Shagen's innocence and pure mind, Li transforms from a wolf to a shepherd; she guards the flame of the best part in humanity and the spectrum of virtue.

\section{The Wolf Metaphor}

On aspect of the moral values, A World Without Thieves entails ethical ambiguity in figures' construction, especially in the case of Bo. While Shagen is portrayed as pure virtuous and innocent, in contrast, Uncle $\mathrm{Li}$ is sheer evil. Bo's ambiguity proves that he lingers between two poles. In this film, Bo anchors his identity as a freelancer, a hungry wolf who struggles to survive in society in an allegorical sense. Under the guidance of such logic, he abandons any virtue bond that might prevent theft. Notably, Bo's personal identity is ambiguous; he avoids using the word "thief" to describe himself. Rather, by using the metaphor of wolf to identify himself, he switches his identity into an ambitious hunter who is driven by survival needs. Such ambiguous definition blurs the moral boundary and legalizes the portrayal of the figure in Chinese system; it also avoids trespassing the boundary set by the censorship system in China.

Bo is agile and smart; his theft skills are outstanding in the thief circuit. He is satisfied with his identity as a hungry wolf rather than as a thief. In his perspective, everything in this world is hypocritical and deceptive, except money. He paralyses himself with constant theft. His happiness derives from theft, by which he gains the sense of existence. When he meets Shagen, his is instinctively antipathic. Bo holds an opposite opinion to Shagen's belief; he despises Shagen's life philosophy at first acquaintance. Deep down in his subconsciousness, he is scared that his belief will be challenged and converted by Shagen's innocence, because his ethical values will be changed accordingly and the source of happiness will be deprived. Thus, out of an instinctive reaction, he expels Shagen and attempts to prove that he is right. From another perspective, there is a pristine space in his heart that remains righteous and virtue, which makes his transformation possible. Later on, he is converted by Li Wang's maternity situation and they wish to raise a baby morally right. So he decides to take the responsibility to protect Shagen's dream and restores him a fantasy that this is a world without thieves. Such choice fits in the censorship system in China. In China, the filmmakers must ensure that their films are ideologically correct to pass the film censorship. Later on, in a crucial moment of life-and-death, Li bestows Bo the lucky pendant that Shagen gave her previously to bless Bo come back safely. In a metaphorical sense, he transforms from evil to virtue. At the moment, Li serves as a moral guild who directs him to the path toward virtue.

To some extent, ideologically, the thieves are employed as a metaphor that mirrors the reality in contemporary Chinese society: the relationships and conflicts between the thief couple and Uncle Li, the relationship between the thief couple and Shagen, and the conflicts between Uncle Li and Shagen are thought-provoking. They symbolize different classes in Chinese society. Whereas Li Wang endows maternity sympathy to Shagen since the beginning, Bo's attitude toward Shagen has changed from antipathy to protection. This phenomenon illustrates that the middle-class accommodates a dual attitude toward the mass, whereas Uncle Li represents the elite class, who remains a durable attitude toward Shagen. He strikes Shagen as he perceives the latter a subversive force to his hegemony and power. Representing the middle class who is drifting from the mainstream, Bo's ambiguous identity enables him to cooperate with both the elite class and the mass. However, only a consolidated cooperation between the middle class and the elite class can construct a stable society; in this light, this film profoundly reflects contemporary Chinese social structure. 
Such setting illustrates the ongoing political discourse in contemporary China: This strife is an epitome of the relationship between the privileged and the underprivileged. Essentially, the two cohorts of thieves/elites belong to the same class. The plot setting evades a storyline that they conspire to steal Shagen's money. With such a strategical setting, the director evades portraying the conflicts between the elite and the uprooted class, which is the real social conflict. This film also grants a silent denounce toward social injustice and improper wealth accumulation. The thieve couple drives a BMW car, which signals their wealth. They also have a huge amount of savings in bank, so they are portrayed as successful elites in the thieves' circuit. These details unfold the sprawling expansion of the commodity fetishism and tell the audience that wealth inequality is soaring.

In contrast to Shagen's hard working and comparably small amount of savings, their wealth is accumulated improperly and quickly, which draws a link to social injustice and uneven wealth distribution. Their maneuver of making a living lacks integrity, so they are immoral and corrupted. In this case, Feng's discontent with social injustice offers an index to political orientation, which directs the audience's attention to an unfairness that virtuous people will not be rewarded in reality. He also reminds the audience of the consequences of moral collapse. However, the thief couple's decision of quitting theft and returning to the right track is conditional: Their moral redemption is because of maternity, though the moral redemption is fulfilled at the cost of life. Bo's moral redemption serves as a warning sign of the declined morality in an era that the nouveau-riche flaunts. His tragic fate terrifies the audience that wealth comes at a cost, even life. Once sin or crime is made, any attempts of redemption are futile. Such value is reinforced by the double-layered tragedy in the end; Li has to raise up a baby alone. Moreover, Bo's moral redemption is just out of guilt, which renders his death fatal and inevitable. To him, death is unpacked in a form of self-deconstruction, and penalty for his previous crimes. His fate also demonstrates a cause-and-effect social mentality. Besides sheer entertaining effects, this commercial film serves as an agency of cultural intervention as well as a mediator plays the role of pedagogy, which eventually demonstrates the entrenched social order and norms.

The last episode of the film unpacks sentimental melancholy while conveying a pedagogical expression in a metaphoric way. Five month later, Li's maternity is conspicuous. She is having a lavish dinner in a restaurant while a plain clothes police officer approaches her. The camera adopts a high angle shot; then a close-up casts her fear and vulnerable sensations in her eyes. Then she conceals her fear with composure and tries to eat more. The camera takes a medium shot to encompass two figures in one frame with in-depth shooting. The police officer makes an implicit expression regarding Bo Wang's death, he says, "Don't wait for him”. Li responds: "Wait, tell me after I finish my dinner”. Then a close-up zooms in Li’s facial expression. There is an emotional tension on her face: She attempts to distract her sadness by consuming more food. This scene is imbued with humane concerns and warmth, because Li is not apprehended. Meanwhile, a sound track gently springs up, bringing back her last memory with Bo. As the train moving forward, a bloody hand firmly holds the strap of Shagen's bag, a trope that Bo is protecting Shagen's utopian dream; in contrast, Shagen still lingers in his dream. Then a close-up on the bloody hand is dropping down feebly by Shagen's side, which indicates Bo shows no signs of life. Meanwhile, a close shot shows that Bo's blood overflows the ground. While Bo redeems his sin with his life and his protection of Shagen's dream, Li's sacredness of maternity and her desire of converting herself to goodness exempt her from being arrested.

\section{The Metaphor of Wolf-and-Sheep and Investigation on Human Nature}

The metaphor of sheep-and-wolf relationship penetrates throughout the whole film. In the filmic text, from 
the interpersonal conversations, the setting is identical: "Thieves are wolves, and the society is composed of sheep and wolves". "Good/innocent people are sheep, while evil people are wolves”. In this discourse, the source domain is thieves/good people; the target domain is wolves/sheep. The target domain is mapped out in film through conversations and frequent repetition in dialogues and images. It is both a visual and verbal metaphor. According to Carroll (1994, p. 190), "visual metaphors use pictorial or otherwise visual devices that suggest identity in order to encourage metaphorical insight in viewers." So wolves and evil people, the "two physically noncompossible elements" are "saliently posed in ... a homospatially unified figure” (1994, p. 214). The conversations and images are starkly juxtaposed with conversations to configure visual metaphors, a binary of wolves-and-sheep metaphor, which is a verbally noticeable integrated entity. In the context, the juxtaposed element inspires an explicit metaphorical thinking. The metaphorical expression links two domains, through which the society is divided into binary poles. Theoretically, the society is composed of good and evil people. Such a division cues an introspection of human nature as well.

In the opening sequence, in a medium shot, Shagen is surrounded by a flock of wolves in a prairie; then he fights his way out. This shot does not simply represent the relationship between Shagen and the wolves, but also the relationship between sheep and wolves, and can be expanded to human's society accordingly. In this film, wolf is a metaphor that represents thieves; it also symbolizes a violent and bloody rivalry rapport for survival in real life. In sharp contrast, sheep represents a cohort of innocent and benevolent people, such as Shagen. It also symbolizes the purest and the most innocent mind. The metaphor establishes a connection between the behaviors and features of animal and vividly projects an epitome of human's society. In one word, the metaphor "conveys the information that leads to the identification of target and source" (Forceville, 2002, p. 8) and "connected images to suggest an emotion or a concept to the spectator" (Carroll, 1996, p. 129).

The strife between wolf and sheep signals metaphorical meanings and can be understood as a formation of the inner struggle between two sides of human nature: the virtue aspect verses the evil one. In this way, the director utilizes film to intervene society by infusing the mainstream values. Bo knows the imperfection of the world clearly; his fate exemplifies the consequences of being a trespasser of the social rules.

There is some strife between $\mathrm{Bo}$ and $\mathrm{Li}$; the first one occurs in the opening sequence. Inspired by maternity catharsis, Li worships the Buddha faithfully for the blessing of her unborn baby when passing by a temple. Later on, she extrudes the idea of quitting the thief career to return to the right track, because she wants to raise up her baby right. She firmly believes that the faithful wish connects a path to catharsis and self-redemption. But Bo totally objects to this idea; then they split up and Bo drives away and leaves Li alone in the desert.

The first strife unfolds Shagen's debut. When $\mathrm{Li}$ is abandoned in the desert alone and pleas for help from passersby, no one stops to help her except kind-hearted Shagen. That is their initial acquaintance. The debut of Shagen drives the storyline to move forward. Later on, in the train station, Li meets Shagen again. Shagen announces his belief publicly that there are no thieves in the world; he shouts out "Who is thief? Stand up and show me! See? No one! The wolves didn't hurt me when I built up and fix the temples, how could humans hurt me?” Shagen's innocent and blunt claim attracts the attention of a gang of thieves and the thief couple as well. $\mathrm{Li}$ recognizes Shagen is the one who offers her help when she was in despair. So they accompany each other to embark the journey. In the context, Shagen perceives the thieves as wolves, and considers himself an innocent sheep, who was not “eaten” by the wolves. The metaphor vividly portrays the characters' personalities. 
Both Uncle Li and Bo want to steal his money, while Li wants to protect his money and his innocent belief. To Li, Shagen is vulnerable and needs protection when confronting the corruptive and dismayed real world. The redemption between them is mutual: Shagen gradually moves $\mathrm{Li}$ with his virtue of innocence and benevolence. His virtue brings Li out of the loop of being evil (as a thief) and wants to guard his innocent dream; she also regards it a chance of redemption for her maternity to raise her unborn child properly. It is Shagen's innocence and virtue that recall the thief couple's conscience and bring them back to the right path. In this sense, Shagen offers spiritual redemption to the thief couple.

The second strife revolves around whether Bo should steal Shagen's money or not, or whether he should guard Shagen's fantasy instead, the thief couple have a debate over this issue. Li persuades Bo to give up the idea of stealing Shagen's money; rather, he should take the responsibility to protect Shagen's money. But Bo disagrees with Li. Bo employs the metaphor of sheep and wolves to persuade Li to give in. They have a furious debate regarding whether they should protect Shagen's innocent illusion or not. In this case, the metaphor of wolves is a verbal one.

Bo believes that they should not hide the true facets of the world to Shagen by veiling his vision to undergo the cruelty of life. They should not deprive people like Shagen's rights to experience the real world. People should acknowledge the scary true cruelty rather than weltering in the polished perfection, because they eventually have to confront the brutal reality. Then the phenomenal peace is just a plain lie, which hurts even more. Such dialectical logic reveals the truth of this world: The world is not impeccable, and one has to comply to the rules in order to survive.

The metaphor of sheep-and-wolves binary provokes a discussion regarding human nature as well. As a symbol of virtue, Shagen represents the goodness of human, yet he is vulnerable, lacks of self-protection skills, and unable to keep his dream intact. The truth is that we live in a world with thieves; the dark side of human's behavior is pertaining to human's nature. However, this film still displays the glorious aspects of human nature, such as the sacredness of maternity, the forgiveness of the policeman in the coda and persistency in one's belief.

As a matter of fact, innocent people suffer from social inequalities resulted from hierarchy. In debit to full efforts of the thief couple, Shagen's naive illusion remains integrated. But it still remains a pending issue: How could he go through and survive when confronting threats in other situations? Therefore, the threats to the innocent people still remain pending. It is inevitable that Shagen's dream eventually will be broken. In brief, the plot setting is sheer utopian given Shagen's dream remains intact in a cruel environment, which violates the laws of reality in China. Such strategy aims at deluding the social infatuations. This film also warns the audience that a person with sheer virtue cannot survive in a society combined with good and evil.

\section{The Metaphor as an Epitome of Social Class}

As an epitome of social class and social stratification, the film portrays a three-layered strife among the social members: Uncle Li and Bo, Uncle Li and Shagen, and Li Wang and Bo. In order to get Shagen's money, Bo takes several contests with Uncle Li's thief gangster team and he defeats them effortlessly. With the money, he is ready to leave with Li Wang. When Li knows the fact, she tells Bo that she is pregnant and she wishes Bo can do some virtual deeds for their unborn baby to pay off their previous sins.

This film is an epitome of social transformations in postsocialist China. The director mediates the dilemmas arose during social transitions, such as illustrating the changing roles of cities in people's lives; 
outlining the anxiety arose from the spiritual sanity in an age of social transitions with the expansion of the commodity fetishism. In this film, the metaphors play a key role in generating a complex discourse of power relations amidst different social forces, classes, and social structure, as well as creating a warning sign to the audience and epitomizing the social reality. The cultural space in film unfolds ideological relocation in contemporary in China, which is undergoing dynamic social transitions; it also signals an epoch transits from Maoist collectivist mode to one that values individualism, from a national constructive narration to self-definition, and from political totalitarianism to the construction of a civic society with more personal freedom.

At first glance, the major protagonists in A World Without Thieves all seem to be uprooted classes. After a careful scrutiny, Uncle $\mathrm{Li}$, who is the leader of the gangster thief, represents the elite class in society and possesses privileges and power. Although Bo Wang belongs to the same social strata with Uncle Li, but he is in a lower status in the power structure; therefore he has to be dispatched on service by the former.

Shagen stands for the grassroots in contemporary Chinese society, who is considered as an unenlightened, unstable force and processes a subversive and deconstructive power; he is considered to consume social resources from the perspective of the social democrats. His status is identified as the "sheep". The main purpose of the figure setting is to provide a spiritual catharsis in the filmic text. In the climax, to guard his money, a bloody fight is going on the stage; Shagen has no awareness of the life-and-death wrestling. Based on this scene, we can discern the attitude of the director who offers a discriminable sympathy to Shagen, as the latter represents the social mass and does not have the capacity to make his life sustainable. Shagen's unrealistic fantasy reveals the unwritten rules of society that this society is composed of "wolves" like Uncle Li, who eats the "sheep", and the innocent people represented by Shagen.

In general, Uncle Li and Bo belong to the same class; both of them are predators in the jungle, whereas Shagen is the preda. Such antagonist between two males not only signals a hidden violence as a spectatorship, but also indicates the contest on power and capital dominance in the internal elite group. Such setting is selective and demonstrates a strategical mentality; it transfers the real conflicts by veiling the cruel reality. It is quite noticeable that the conflict exists between the predator and the prey rather than within the elite group internally. The narrative tactfully refocuses on the conflicts between the internal privileged groups, rather than the privileged and unprivileged groups. Furthermore, the privileged even provide shelter to the marginal group. In this way, this strategic narrative transfers real issues, such as social injustice, uneven capital distribution, and growing inequality; instead, these issues are soothed in an imaginary space.

In a broad sense, the figure of the grassroots like Shagen is just a disguised form, under which he represents the uprooted class in contemporary China, who struggle to survive at the bottom of pyramid of the power structure. Bo's attitude toward Shagen shows that the elite group grants limited sympathy to the lower class. Such sympathy also carries an underlying tone of discrimination, in which the competent man overlooks his opponents who are weak. Another scenario illustrates this point is the fight scene between Uncle Li and Bo on the train. In a sharp contrast, Shagen is immersing in dreams, bearing no awareness of the undercurrent around him.

\section{Conclusion}

The warning effect of ethical corruption shapes a dim undertone of the film. The death of Bo entails a warning sign and a terrifying effect that cautions the audience, in that reckonings and punishment are inevitable 
for those who are morally collapse. Once a sin is committed, even moral redemption at the cost of life cannot extricate the previous sin. In this aspect, this film goes beyond sheer entertaining effects; there is a hidden ideological conservative index within the text, which is articulated through the death of the male protagonist. Such plot setting shows the director's embracing on mainstream values by terrifying the audience of the brutal consequences of misbehaves in a nuanced manner.

Feng has a deep understanding toward contemporary Chinese society; the metaphor of "the wolf and the sheep" imbues cultural significance, which represents two different groups of people sharing different perspectives and values. In this context, human nature is dichotomized into good virtues and sheer evil. The metaphor vividly maps out an ongoing social sphere in China now. The division also accentuates class stratification in China; the rampant capitalist gives rise to social injustice and social stratification. In this light, socialist ideology is invoked as a dose: It can only sooth the conflicts, but cannot solve the problems from the root.

Besides employing the metaphor of sheep and wolves, this film also incorporates the images of police officers as the metaphor of social order, justice and authority. On the train where staging the cat-and-mouse game, the plain clothes police officers function as a symbol of social authority, as well as a tangible terrifying force. When they arrived at the criminal spot, a brutal fight between two forces, Uncle Li and Bo, is just over. As a result, Bo is killed. Before his death, he returns Shagen's money and guards his fantasy of the world. In contrast, the police officers did not fulfill their responsibilities of protecting the good and punishing the evil. In the coda, serving as a metaphor of the authority, they arrest the thieves effortlessly without devoting efforts. The director presents a spectrum of his mundane concerns on implicit social critiques; he terrifies the audience of the social rules and mainstream ethical values.

Serious social problems like migrant workers remain an unsolved issue in this film, which are unpacked in the format of farces. Migrant workers expose social problems in contemporary China, such as the unevenness in wealth distribution, unemployment, and housing issues. The emergence of migrant workers resulted from the process of urbanization and industrial development, during which a massive scale of labor forces was sprawling into cities and spurring their growth. However, the economists and sociologists consider them as an unstable force because of their mobility. After Shagen gets back to his hometown with 60,000 RMB, how can he find a job in the shrinking job market and make a living? As there are many other migrant workers and marginal figures as innocent as Shagen, do they have shelters and protectors when they are confronting with similar situations? However, this world will become sheer evil if the majority are wolves. Therefore, Feng adopts a balanced and moderate manner in his expression.

The metaphor helps to unfold the social conflicts in contemporary China. The conflicts on the train are highly selective, which are not aimed to demonstrate the strife between the underprivileged and the privileged; rather, the conflicts are transferred into the inner class-among the privileged group members. The privileged class, such as Li Wang and Bo Wang, make full efforts to guard the underprivileged—Shagen's dream intact against their peer Uncle Li, who belongs to the same class with them. This strategical narration transfers the social controversy tactfully.

Such ramification is expressed in a silent way through the storyline. The warning effects shape the overall undertone of the film: Ethical corruption, reconciled redemption, and tragic fate are envisioned. Feng also warns his audience that once one is dominated by the desire of money-hunger, he steps toward an unfathomed 
abyss of moral decline whereas redemption could only be made in vain. At this point, this film illustrates the morality and one's fate in an allegorical sense.

In conclusion, casting the thieves as the predator in society, Feng incorporates metaphors to illustrate serious social stratification which is plaguing throughout Chinese society. However, he provides no positive solutions for such social issues.

\section{References}

Berry, C., \& Farquhar, M. (2004). China on screen: Cinema and nation. New York: Columbia University Press.

Braester, Y. (2005). Chinese cinema in the age of advertisement: The filmmaker as a cultural broker. The China Quarterly, 183, 549-564.

Braester, Y. (2010). Painting the city red: Chinese cinema and the urban contract. Durham: Duke University Press.

Careel, N. (1996). A note on film metaphor. In Theorizing the moving image (pp. 212-223). Cambridge: Cambridge University Press.

Carroll, N. (1994). Visual Metaphor. In J. Hintikka (ed.), Aspects of Metaphor (pp. 189-218). Dordrecht: Kluwer.

Chan, K. (2009). Remade in Hollywood: The global Chinese presence in transnational cinemas. Hong Kong: Hong Kong University Press.

Chow, R. (2007). Sentimental fabulations, contemporary Chinese films: Attachment in the age of global visibility. New York: Columbia University Press.

Dai, JH. (2005) Feng Xiaogang gui lai (The Return of Feng Xiaogang), Bai jia jiangtan, China Central TV (CCTV) Channel Ten, February 4.

Goatly, A. (2007). Washing the Brain. Metaphor and Hidden Ideology. Amsterdam: John Benjamins.

Gong, H. M. (2009). Commerce and the critical edge: Negotiating the politics of postsocialist film, the case of Feng Xiaogang. Journal of Chinese Cinemas, 3(3), 193-214.

Kong, S. Y. (2003). Big shot from Beijing: Feng Xiaogang's lie Sui Pian and contemporary Chinese commercial film. Asian Cinema, 14(1), 175-187.

Lakoff, G. \& Turner, M. (1989). More than cool reason: a field guide to poetic metaphor. Chicago: University of Chicago Press.

Lakoff, G. (1987). Women, fire, and dangerous things: What categories reveal about the mind. Chicago, London: University of Chicago Press.

Lakoff, G. (2001a). Cognitive linguistics. Retrieved from http://www.clas.ufl.edu/ipsa/journal/2001_lakoff01.shtml

Lakoff, G. (2001b). How metaphor structures dreams: The theory of conceptual metaphor applied to dream analysis. Retrieved from http://www.clas.ufl.edu/ipsa/journal/2001_lakoff02.shtml

Lakoff, G., \& Johnson, M. (1980a). Metaphors we live by. Chicago and London: University of Chicago Press.

Lakoff, G., \& Johnson, M. (1980b). Conceptual metaphor in everyday language. The Journal of Philosophy, 77(8), 453-486.

Lu, S. II. (2001). China, transnational visuality, global postinodernity. Stanford, California: Stanford University Press.

McGrath, J. (2008). Postsocialist modernity: Chinese cinema, literature, and criticism in the market age. Stanford: Stanford UP.

Semino, E. (2008). Metaphor in discourse. Cambridge: Cambridge University Press. 